\title{
IMPROVING PROPERTIES OF SINGLE CRYSTAL TO POLYCRYSTALLINE CAST ALLOY WELDS THROUGH HEAT TREATMENT
}

\author{
A.E. Kolman \\ General Electric Power Systems, Schenectady, NY 12345
}

\begin{abstract}
$\underline{\text { Abstract }}$
Joining between single crystal and polycrystalline cast materials is dcsirable for advanced steam cooled land based gas turbine airfoil components. Electron beam weld joints between single crystal Rene N5 and polycrystalline GTD-222 have been characterized in terms of microstructure, crystallographic orientation, low cycle fatigue behavior, and chemistry across the weld centerline. The weld centerline was shown to be the vulnerable area of the joint due to carbide segregation and crystallographic mismatch. In addition, the weld fusion zone hardness was significantly higher than that of either base material. The effect of several proposed heat treatments on weld hardness was examined. All of the heat treatments significantly reduced weld hardness as compared to a standard GTD-222 solution treatment and age cycle. Scanning electron microscopy analysis revealed the hardness drop was due to coarsening of gamma prime in the weld fusion zone.
\end{abstract}

\section{Background}

Directionally solidified or single crystal cast nickel based alloys are key matcrials for high efficiency land based gas turbine components. While one piece castings are commonly utilized for rotating airfoils, fabricated assemblies are possible for stationary parts, offering the opportunity to use lower cost polycrystalline structures for portions of the assembly away from the hot gas path. Joining studies of single crystal to polycrystalline material have mainly explored diffusion bonding techniques ${ }^{1,2}$. Challenges for this technique include determining the optimal bonding HIP/heat treatment cycle for two dissimilar materials, and practical joining of non-planar components.
Studies of fusion welding of single crystal or polycrystalline gamma prime strengthened alloys have focused on causes of weld cracking ${ }^{3,4}$, often from strain age cracking ${ }^{5,6}$. Little activity has been reported on the metallurgy of single crystal to polycrystalline fusion weld joints. Weld properties of single crystal to polycrystalline superalloy joints can be less than optimal due to abrupt changes in crystallographic orientation near the weld centerline, the propensity for carbide precipitation near the weld centerline, and the high hardness of the weld compared to the base materials, all contributing to early centerline failure in low cycle fatigue (LCF) testing. These contributing factors are examined in the following study for Rene N5 to GTD-222 electron beam welded joints.

\section{Experimental Procedures}

Compositions of GTD-222 and Rene N5 are shown in Table I. Cast slabs of GTD-222 and Rene N5 were welded together using an autogenous electron beam weld process. The slab thickness was reduced in the area of the weld to $0.76 \mathrm{~cm}$. The welded slabs were subjected to the GTD-222 solution and age heat treatment cycle $\left(1150^{\circ} \mathrm{C}\right.$ for 4 hours, and $800^{\circ} \mathrm{C}$ for 8 hours), followed by a fluorescent penctrant (FPI) and $\mathrm{x}$-ray inspection. Curved strips were cut from the slabs, with the weld in the center of each strip, yielding small disks between each pair. Round bar LCF specimens were machined from the curved strips, excluding any areas containing indications. The specimens were $11.7 \mathrm{~cm}$ long, with a $1.5 \mathrm{~cm}$ grip diameter and $0.76 \mathrm{~cm}$ gage diameter. The gage length was $1.5 \mathrm{~cm}$, with the autogenous weld at the center of the gage section. FPI inspection was performed again after specimen machining to exclude test bars with indications from LCF testing. The disk remainders were mounted, polished and etched for microstructural evaluation.

Table I: GTD-222 and Rene N5 Compositions

\begin{tabular}{|c|c|c|c|c|c|c|c|c|c|c|}
\hline & $\mathrm{Ni}$ & $\mathrm{Cr}$ & $\mathrm{Co}$ & $\mathrm{Mo}$ & $\mathrm{W}$ & $\mathrm{Nb}$ & $\mathrm{Al}$ & $\mathrm{Ti}$ & $\mathrm{C}$ & $\mathrm{Ta}$ \\
\hline GTD-222 & balance & 22.5 & 19.1 & - & 2.0 & 0.8 & 1.2 & 2.3 & 0.08 & 0.95 \\
\hline Rene N5 & balance & 7.0 & 7.5 & 1.5 & 5.0 & - & 6.2 & - & 0.05 & 6.5 \\
\hline
\end{tabular}




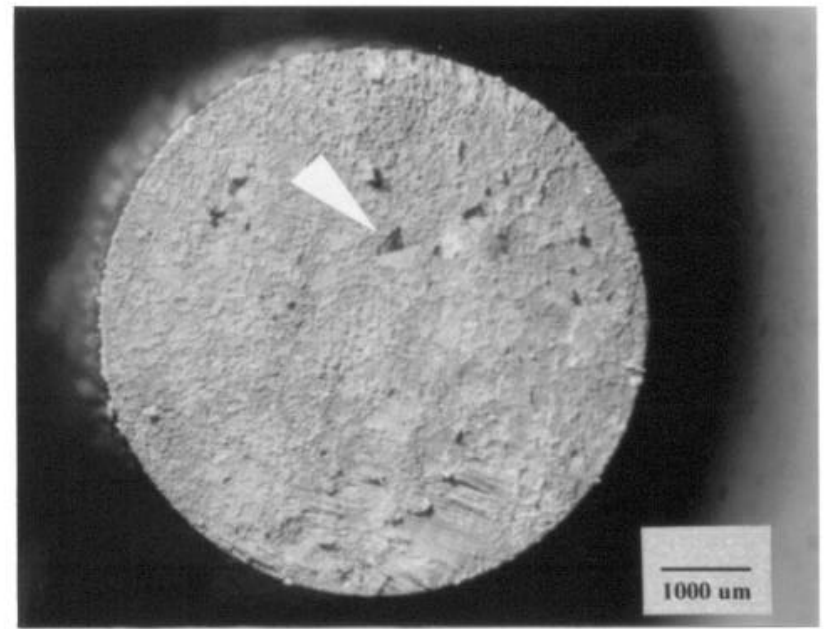

Figure 1: Fracture surface of $870^{\circ} \mathrm{C}$ LCF test specimen, Rene N5 side, with pyramid indentations.

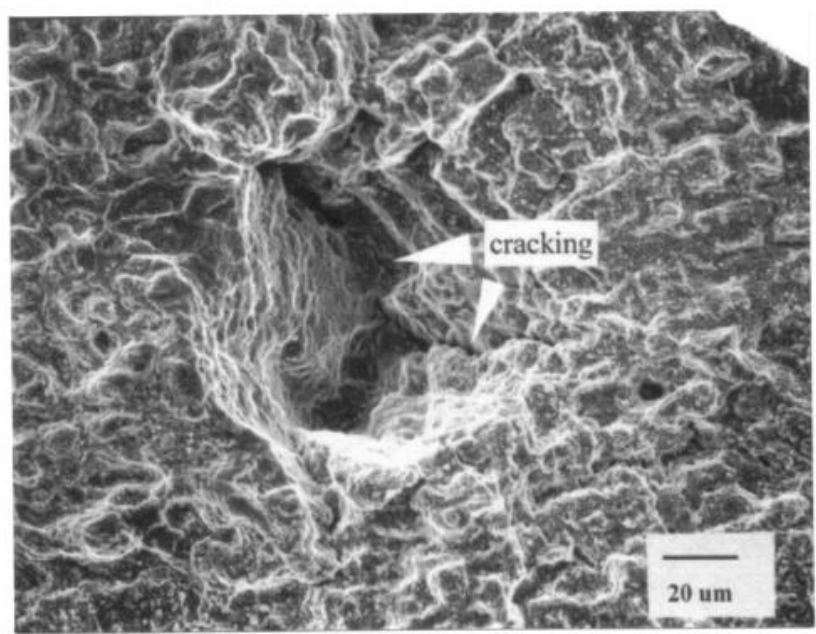

Figure 2: Pyramid indentation on Rene N5, with sidewall and apex cracking.

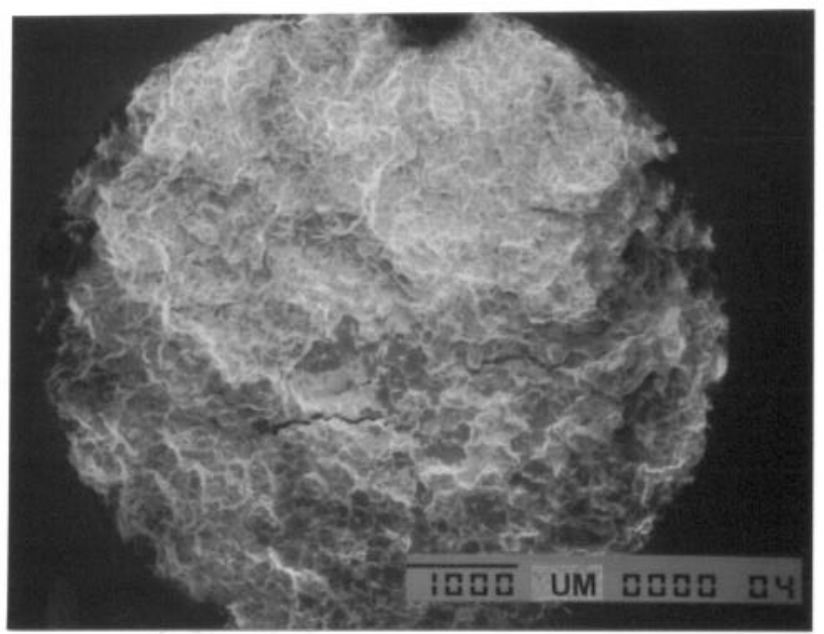

Figure 3: Fracture surface of $760^{\circ} \mathrm{C}$ LCF specimen at the GTD222 fusion line with secondary intergranular cracking.

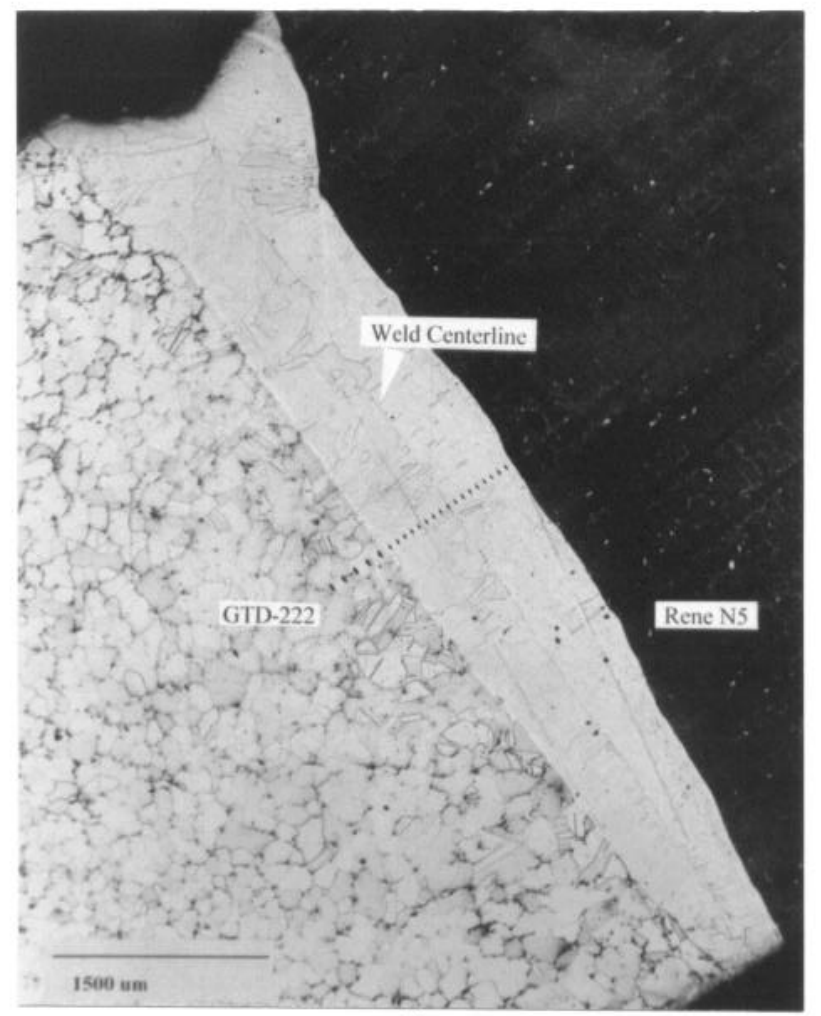

(a)

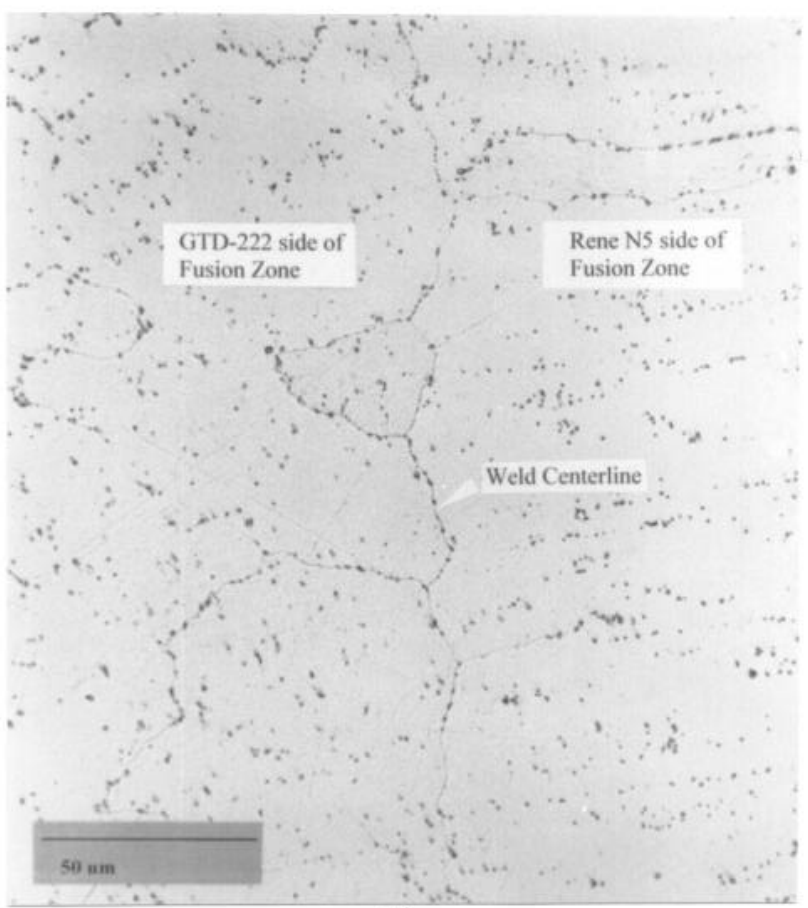

(b)

Figure 4: Cross-section of autogenous Rene N5 to GTD-222 electron beam weld at a) low magnification b) high magnification. 
LCF specimens were tested with a two minute hold time in tension under strain control at $650^{\circ} \mathrm{C}$ and $760^{\circ} \mathrm{C}$. A two minute hold time in compression was necessary for $870^{\circ} \mathrm{C}$ testing, because excessive yielding of the material occurred under tensile hold conditions at $870^{\circ} \mathrm{C}$.

\section{$\underline{\text { Results and Discussion }}$}

\section{$\underline{\text { LCF Behavior }}$}

A specimen tested at $870^{\circ} \mathrm{C}, 0.40 \%$ strain achieved only $6 \mathrm{LCF}$ cycles prior to failure, with flat, interdendritic fracture occurring at the weld centerline (figure 1). Small pyramid structures were observed on both fracture surfaces, but primarily on the GTD222 side. Examination by electron microprobe revealed these structures were not titanium or tantalum-rich, as would be expected for MC carbides. Rather, the pyramids were identical in composition to the rest of the fusion zone. The pyramid indentation in figure 2 shows a convergence of dendrite arms at the apex, with sidewall cracking that led to pyramid separation.

A higher number of cycles to crack initiation were achieved at the lowcr temperature, lower strain test conditions. Bars tested at $760^{\circ} \mathrm{C}$ with $0.30 \%$ and $0.50 \%$ strain achieved 1237 and 2 cycles, respectively, while bars tested at $650^{\circ} \mathrm{C}$ with $0.55 \%$ and $0.72 \%$ strain failed after 4908 and 414 cycles. Specimens tested at the lower temperatures exhibited more intergranular fracture surfaces than the $870^{\circ} \mathrm{C}$ specimens, and typically had some or all of the fracture occur at the GTD-222 fusion line (figure 3).

\section{Microstructure Characterization}

Remainder disks from the welded slab were cross-sectioned, mounted and examined. The weld centerline was linear and highly decorated with tantalum- and titanium-rich carbide precipitates. MC-type carbides were also evident within the fusion zone grain boundaries (figure 4).

Element plot traces across the fusion zone were generated by electron microprobc (figure 5). To improve clarity of lower weight percent elements, $\mathrm{Cr}$ was omitted from the plot. The fusion zone composition is biased towards the GTD-222 composition (table II).

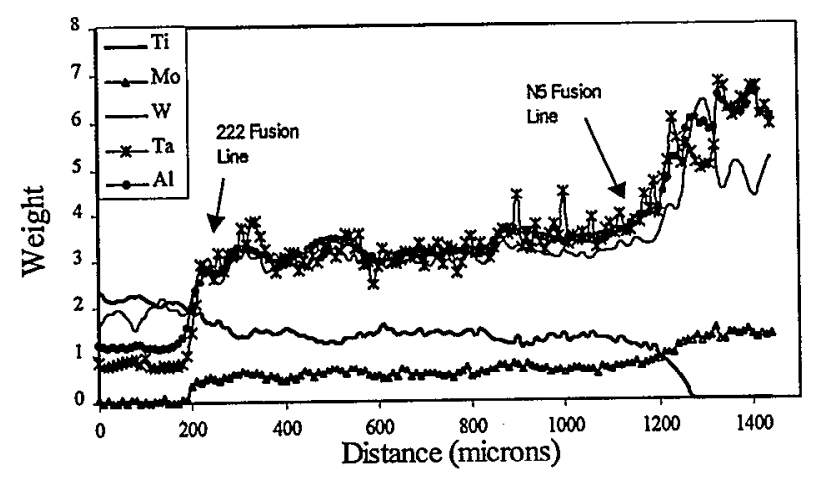

Figure 5: Microprobe traces across the Rene N5 to GTD-222 weld after GTD-222 solution treatment and age.
Table II: Fusion Zone Composition Comparison

\begin{tabular}{|c|c|c|c|c|}
\hline & GTD-222 & Rene N5 & $\begin{array}{c}\text { Calculated } \\
\text { Mean } \\
\text { Composition }\end{array}$ & $\begin{array}{c}\text { Measured } \\
\text { Fusion Zone } \\
\text { Average } \\
\text { Composition }\end{array}$ \\
\hline $\mathrm{Cr}$ & 22.5 & 7.0 & 14.75 & 16.3 \\
\hline $\mathrm{Ti}$ & 2.3 & 0 & 1.15 & 1.5 \\
\hline $\mathrm{Mo}$ & - & 1.5 & 0.75 & 0.75 \\
\hline $\mathrm{W}$ & 2.0 & 5.0 & 3.5 & 3.0 \\
\hline $\mathrm{Ta}$ & 1.0 & 6.5 & 3.75 & 3.3 \\
\hline $\mathrm{Al}$ & 1.2 & 6.2 & 3.7 & 3.3 \\
\hline
\end{tabular}

\section{Crystallographic Orientation}

Coupon disks were metallographically mounted and analyzed by Electron Backscatter Pattern (EBSP) analysis. This technique provides real time diffraction patterns on bulk specimens. The EBSP plot of the weld fusion zone (figure 6) shows crystallographic orientation differences in the single crystal Rene N5 to equiaxed GTD-222 weld joint. The weld centerline is an interface between low and high angle boundary regions, corresponding to single crystal and polycrystalline regions, respectively. The Rene N5 side of the fusion zone formed epitaxially from the base material. The GTD-222 side of the weld is comprised of random high angle grain boundaries. The GTD-222 base material has a mixture of random and twin boundaries. The sharply defined crystallographic boundary at the center of the fusion zone predisposes centerline failure.

\section{Weld Hardness}

Knoop hardness traverses across the fusion zone were measured on coupon disks. Hardncss readings were significantly higher in the fusion zone compared to either base material after GTD-222 solution and age heat treatments (figure 7). Deleterious effects of excessive hardness in the fusion zone have been shown in laser welded Waspaloy ${ }^{7}$ and laser welded Hastelloy X to Mar$\mathrm{M} 247^{8}$. In the autogenous Waspaloy welds, the hcat affected zone (HAZ) remained hard even after solution and age heat treatments. During subsequent LCF testing, cracks initiated predominantly at the fusion zone / HAZ boundary. In the case of wrought Hastelloy X welded to cast Mar-M247, a direct correlation was observed between hardness of the fusion zone and fusion zone cracking. This tendency was reduced by intentional off-center welding into the Hastelloy $\mathrm{X}$ base material.

\section{Effect of Heat Treatment}

Additional coupons from the welded slab were subjected to several heat treatment sequences (table III). The sequences were selected to examine the effects of a Rene N5 age cycle, a Rene N5 stress relief cycle, and fabrication heat treatments. Fusion zone hardness of these test specimens was significantly lower than the hardness of welds which received only GTD-222 solution and age heat treatments (figure 8). Two of the heat treatment sequences lowered the hardness of the Rene N5 base material. 


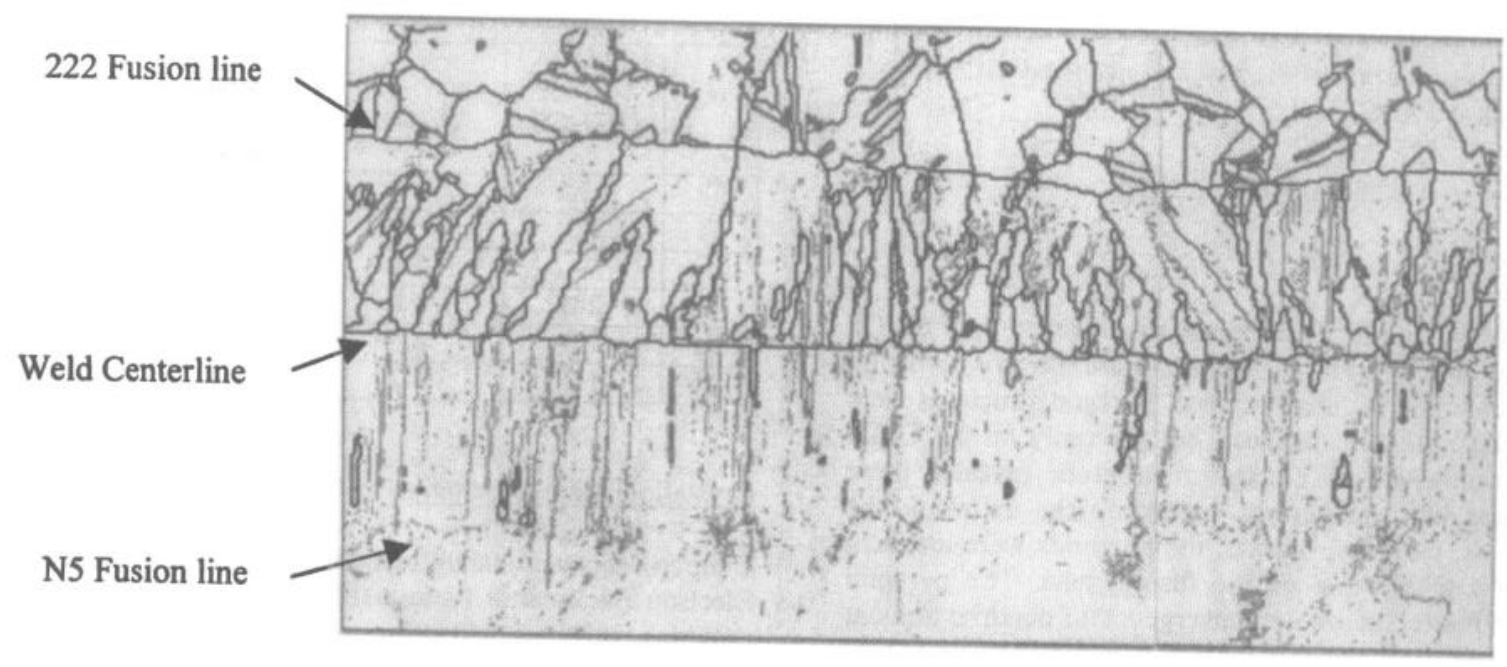

Figure 6: EBSP image of Rene N5/GTD-222 EB weld joint

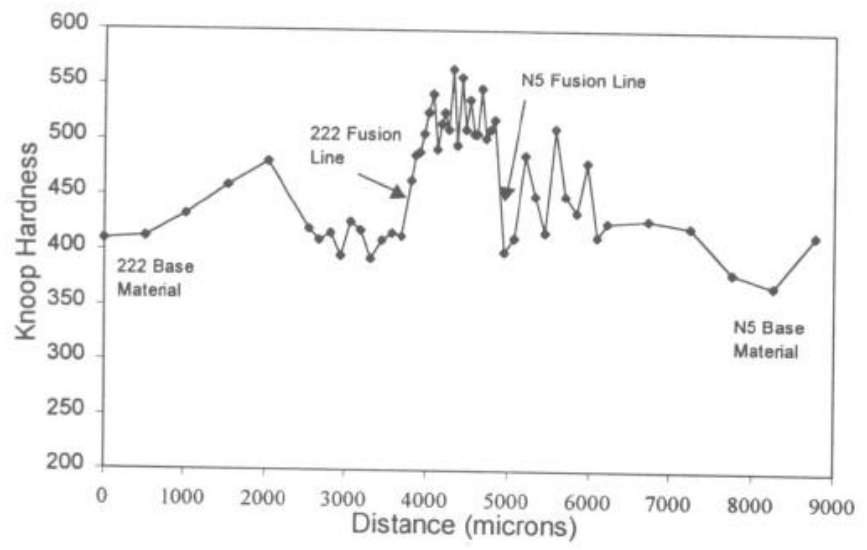

Figure 7: Knoop hardness measurements across the fusion zone of GTD-222 / Rene N5 weld after GTD-222 solution treatment and age.

Table III: Heat Treatment Sequences

\begin{tabular}{|l|l|l|l|l|}
\hline Heat Treatment Sequence & $\mathbf{1}$ & $\mathbf{2}$ & $\mathbf{3}$ & $\mathbf{4}$ \\
\hline $\begin{array}{l}\text { Initial slab HT }(\mathrm{GTD}-222 \text { soln \& age): } \\
1150^{\circ} \mathrm{C} / 4 \mathrm{hrs} ., 800^{\circ} \mathrm{C} / 8 \mathrm{hrs} .\end{array}$ & $\sqrt{ }$ & $\sqrt{ }$ & $\sqrt{ }$ & $\sqrt{ }$ \\
\hline $1150 / 2 \mathrm{hrs}$. & & & & \\
\hline $480^{\circ} \mathrm{C} / 45 \mathrm{~min}$. & & $\sqrt{ }$ & $\sqrt{ }$ & $\sqrt{ }$ \\
\hline$>1040^{\circ} \mathrm{C} / 9 \mathrm{hrs}$. & & $\sqrt{ }$ & $\sqrt{ }$ & $\sqrt{ }$ \\
\hline 222 age: $800^{\circ} \mathrm{C} / 8 \mathrm{hrs}$. & & $\sqrt{ }$ & $\sqrt{ }$ & $\sqrt{ }$ \\
\hline $\mathrm{N} 5$ stress relief: $1210^{\circ} \mathrm{C} / 1 \mathrm{hr}$ & & $\sqrt{ }$ & & \\
\hline $\mathrm{N} 5$ age: $900^{\circ} \mathrm{C} / 4 \mathrm{hrs}$. & & & & $\sqrt{ }$ \\
\hline
\end{tabular}

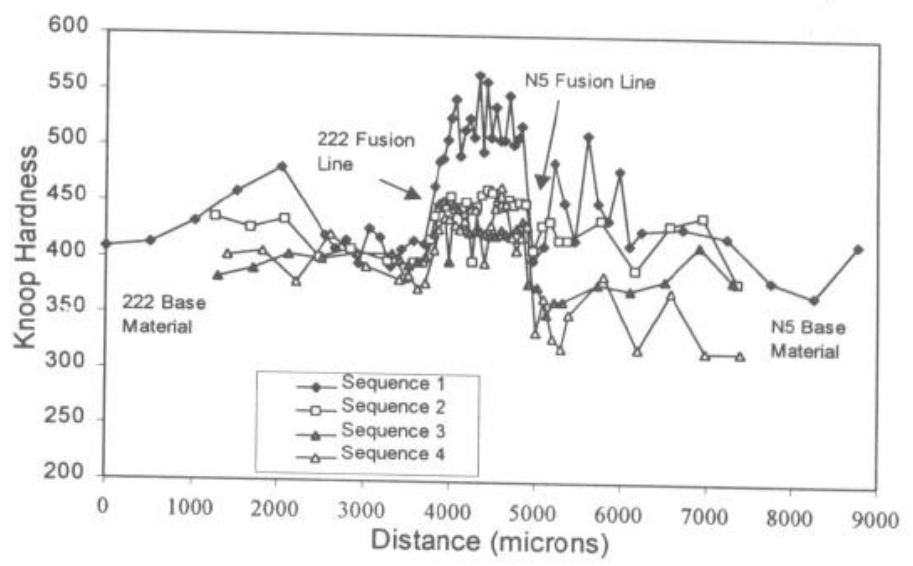

Figure 8: Knoop hardness measurements across the fusion zone of GTD-222/Rene N5 welds following heat treatment sequences $1,2,3$, and 4 .

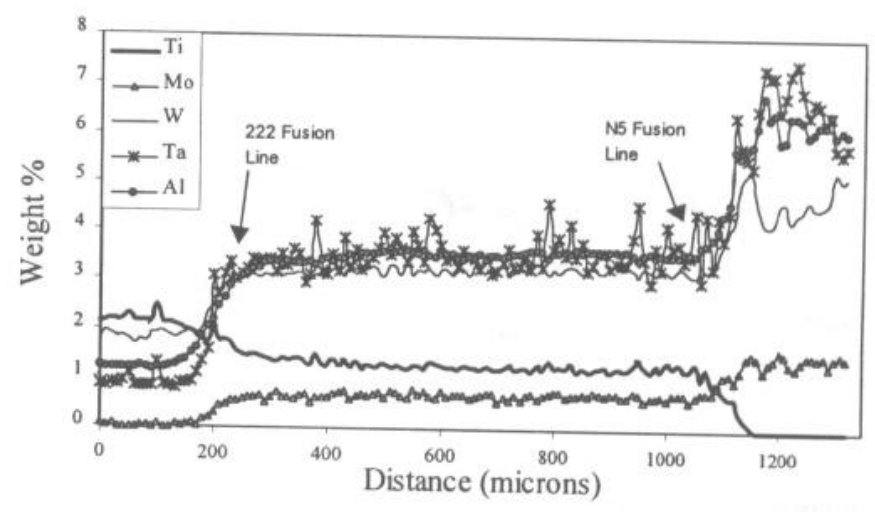

Figure 9: Microprobe traces across the Rene N5 to GTD-222 weld after sequence 2 heat treatment. 
Chemistry differences were not detectable between samples that received different heat treatments. Microprobe traces across the fusion zone of extended heat treatment samples were virtually identical to those of samples treated with the GTD-222 solution and age cycles (figure 9).

Examination of the weld microstructure by scanning electron microscopy revealed the hardness drop was attributable to an increase in gamma prime size. The typical size of gamma prime precipitates in the extended heat treatment specimens was 0.33 $\mu \mathrm{ms}$, compared to $0.10 \mu \mathrm{ms}$ for GTD-222 solution and age treated specimens (figure 10). Agglomerated gamma prime particles of $1 \mu \mathrm{m}$ size were observed in the extended heat treatment specimens.

In another study, overaging Rene 41 prior to welding has been shown to be beneficial in reducing strain age cracking during post weld heat treatment ${ }^{9}$. In the present study, overaging after welding improved weld ductility through reduced hardness. Because the fusion zone was enriched in aluminum from Rene N5 dilution, the gamma prime solvus temperature of the weld was greater than that of GTD-222. The standard GTD-222 solution heat treatment cycle was too low to return gamma prime particles to solution. Subsequent heat treatment sequences caused these particles to grow and overage.

The preferred extended heat treatment is sequence 2, because of the minimal effects on Rene N5 base material hardness.

\section{$\underline{\text { Conclusions }}$}

Examination of single crystal to polycrystalline welds showed a high degree of carbide precipitation along a straight centerline boundary, as well as abrupt changes in crystallographic orientation. Fracture during $870^{\circ} \mathrm{C}$ LCF testing occurred predominantly at the weld centerline. Lower LCF test temperature specimens which had at least a portion of fracture at the fusion zone/base material interface achieved more cycles to crack initiation. The weld hardness after standard GTD-222 solution and age heat treatment was significantly higher than that of the base materials. Extended heat treatment cycles which effected gamma prime overaging resulted in reduced weld hardness. Critical material property requirements of the weld joint and base materials would need to be determined for the specific application prior to employing the overaging strategy.

\section{Acknowledgements}

The author would like to acknowledge Tymm Schumaker at GE Power Systems for SEM analysis; Lou Peluso, Charles Mukira, and Shyh-Chin Huang at the GE Corporate Research and Development Center for electron microprobe and EBSP analysis; and Jack Wood and John Murphy for helpful discussions.

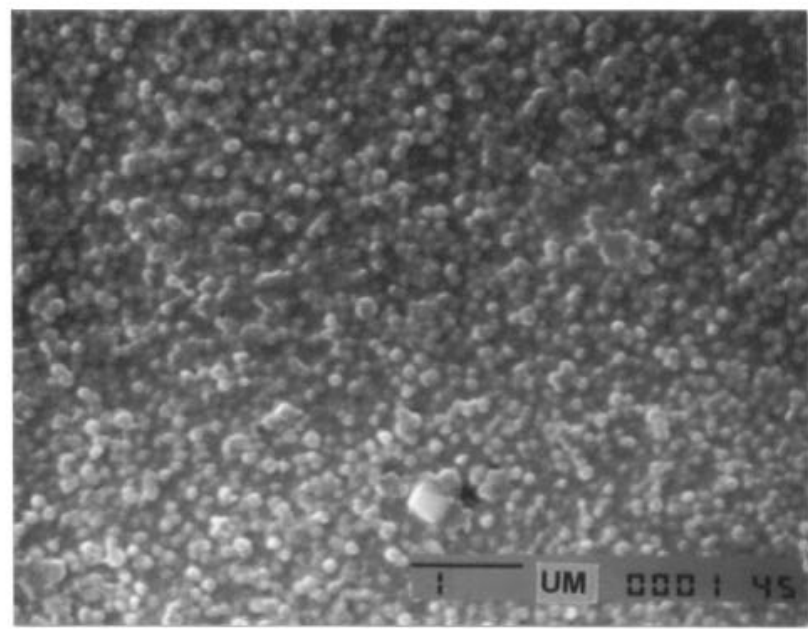

(a)

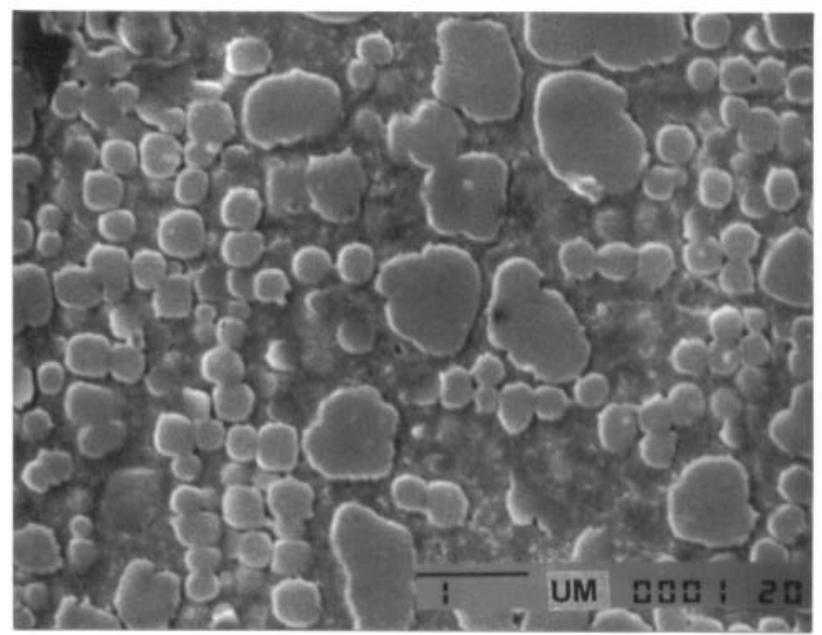

(b)

Figure 10: Gamma prime particles in weld after a) GTD-222 solution treatment and age b) sequence 2 heat treatment. (Scale bar in both photos is $1 \mu \mathrm{m}$ ).

\section{$\underline{\text { References }}$}

1. Y. Bienvenu et al., "Diffusion Bonding of Nickel Base Superalloys to Manufacture Turbine Components with a Graded Microstructure", FGM 94 Proceedings of the $3^{\text {rd }}$ Intl. Symp. on Structural and Functional Gradient Materials, Lausanne Switzerland, Oct 1994, 487-494.

2. R. Larker, J. Ockborn, B. Selling, "Diffusion Bonding of CMSX-4 to Udimet 720 Using PVD-Coated Interfaces and HIP", Journal of Engineering for Gas Turbines and Power, 121 (July 1999), 489-493. 
3. S. A. David et al., "Welding of Nickel Base Superalloy Single Crystals", Science and Technology of Welding and Joining, 2, (2) 1997, 79-88.

4. S. A. David, S. S. Babu, J. M. Vitek, "Weldability and Microstructure Development in Nickel-base Superalloys", Mathematical Modeling of Weld Phenomena 4 (1998), 269-289.

5. C. Sims, N. Stoloff, W. Hagel, ed., Superalloys II (New York, NY, John Wiley \& Sons 1987), 511-516.

6. D. L. Olson et al., volume eds., ASM Handbook Volume 6 Welding, Brazing and Soldering (1993), 572-574.

7. Z. Li, et al., "Metallurgical Investigation of Laser Welds in Wrought Waspaloy", Science and Technology of Welding and Joining, 3, (1) (1998) 1-7.

8. Z. Li, S. L. Gobbi, K. H. Richter, "Autogenous Welding of Hastelloy X to Mar-M 247 by Laser", Journal of Materials Processing Technology, $70^{\circ}$ (1997), 285-292.

9. T. F. Berry, W. P. Hughes, "A Study of the Strain-Age Cracking Characteristics in Welded Rene 41- Phase II", Welding Journal, 48, (1969), 505S-513S. 